\title{
Challenges of Pharmacovigilance in Brazil
}

\author{
Vanessa M. de Oliveira ${ }^{1}$, Vanessa T. Gubert-Matos ${ }^{1,2}$, Alexandre A. Tutes ${ }^{2}$, Cristiane M. Ferreira ${ }^{1}$, \\ Erica F. Vasconcelos-Pereira ${ }^{1}$, Monica C. Toffoli-Kadri ${ }^{2}$ \& Maria T. F. D. Monreal ${ }^{1}$ \\ ${ }^{1}$ Pharmacy School Prof ${ }^{a}$ Ana Maria Cervantes Baraza, Faculty of Pharmaceutical Sciences, Food and Nutrition, \\ Federal University of Mato Grosso do Sul, Campo Grande - MS, Brazil \\ ${ }^{2}$ Pharmacy Post-Graduation Program, Faculty of Pharmaceutical Sciences, Food and Nutrition, Federal University \\ of Mato Grosso do Sul, Campo Grande - MS, Brazil
}

Correspondence: Vanessa Terezinha Gubert de Matos, Pharmacy School, Faculty of Pharmaceutical Sciences, Food and Nutrition, Federal University of Mato Grosso do Sul, Campo Grande-MS, Brazil. Tel: 55-(67)-3345-7781.

Received: August 27, 2020 Accepted: October 21, 2020 Online Published: December 18, 2020

doi:10.5539/gjhs.v13n2p1 URL: https://doi.org/10.5539/gjhs.v13n2p1

\begin{abstract}
Pharmacovigilance encompasses the detection, evaluation, understanding, and prevention of adverse effects or any other drug-related problems. Knowledge of real and independent pharmacovigilance data is essential because clinical trials with medicinal products are limited and do not reveal all adverse effects of a product. The spontaneous notification system is one of the main tools used in pharmacovigilance. However, important remaining challenges for health professionals are the accurate recognition of adverse drug reactions and reporting routinely and systematically during their work. Once low notification rates make it harder to detect and monitor potential safety issues, it is needed risk assessment, and regulatory actions to safeguard patient safety. The objective of this study is to present the challenges of pharmacovigilance in Brazil. The implementation of computerized active search tools significantly improves the identification of possible adverse drug effects. Effective pharmacovigilance is crucial to ensure the safety and integrity of healthcare systems, to avoid lengthy hospital stays and to optimize healthcare spending. However, pharmacovigilance tools remain underused, undervalued, or even unknown in Brazil.
\end{abstract}

Keywords: pharmacovigilance, adverse drug reaction reporting systems, sentinel surveillance, drug utilization, drug monitoring, public health

\section{Introduction}

Medicines are indispensable instruments in the therapeutic scheme of various diseases and can prevent, treat and hinder their progression. However, the irrational use of medicines can cause health damage, such as poisoning and adverse reactions. Brazil is one of the countries with the largest consumption of medicines in the world, occupying, in 2007, the fourth place in the world ranking (Gomes, Silva, \& Galvão, 2017).

According to the World Health Organization (WHO), pharmacovigilance involves the science and activities related to the identification, evaluation, understanding, and prevention of adverse effects or any possible drug-related problem (WHO, 2002). Its main aim is to monitor unknown or rare, undesirable effects associated with the use of certain drugs, which were not detected during the clinical trials, and, furthermore, to inform and educate health professionals about the rational prescription of drugs (WHO, 2015). More recently, the field of pharmacovigilance has been expanded to include other agents, such as herbal products, traditional, and complementary medicines, hemotherapeutic products, biological products, health products, and vaccines (WHO, 2002).

National Pharmacovigilance Centers were developed in most countries after the thalidomide tragedy in the 1960s. The establishment of the International Society for Pharmacovigilance in 1984, and of the European Pharmacovigilance Society in 1992, marked the global introduction and integration of pharmacovigilance in clinical practice. In Brazil, an initiative to broaden and systematize surveillance of products used in health services was taken by the National Health Surveillance Agency in partnership with Brazilian hospitals, developed the Sentinela Network. The aims of this network were to expand the reporting base, to implement notification schemes, and to emphasize pharmacovigilance-related themes in the education of health professionals (Silva, Cornélio, 
Araujo, \& Da, 2014). In Europe, regulatory agencies rely on industry to conduct phase 4 research to varying degrees, resulting in divergent pharmacovigilance policies. In contrast, increased resources available to regulators and public research networks in the US and Canada allow more independent research to shape their decisions. These differentiated policy and governance approaches contribute to divergence in international pharmacovigilance strategies (Wiktorowicz, Lexchin, \& Moscou, 2012).

The availability of independent and valid pharmacovigilance data is essential because clinical trials with medicinal products are limited in scope and do not necessarily reveal all adverse effects of a product (Dainesi, 2005). The lead time for pre-marketing tests is sometimes insufficient for adverse reactions to become manifest and drugs may also be administered to populations or for indications for which they have not been previously tested (Menard et al., 2016). In sum, pharmacovigilance information is essential to support drug regulation and inform pharmacogovernance policies, embodied by government structures, policy instruments, rules, norms, and institutional authority to safeguard societal interests by fostering patient safety and protection from adverse drug events. The objective of this study is to present the challenges of pharmacovigilance in Brazil.

\subsection{Issues in Notification}

The success of any pharmacovigilance system depends greatly on the contributions of health professionals and the general public, as well as on the degree of cooperation and communication with pharmacovigilance centers (Almandil, 2016). However, Adverse Drug Reactions (ADRs) are poorly reported by health professionals, particularly in developing countries. It is estimated that only $2 \%-4 \%$ of all adverse reactions and $10 \%$ of severe ADRs are reported worldwide (Hazell \& Shakir, 2006). From 2008 to 2013, the Brazilian average annual notification rate was 25 notifications $/ 1,000,000$ inhabitants. This rate is considerably lower than those proposed in the international literature, which suggests 300 notifications /1,000,000 inhabitants (Pepe \& Novaes, 2020).

Important obstacles faced by health professionals which may reduce the number of ADR notifications, include the required effort and time, as well as uncertainty about the correct diagnosis. The lack of human resources burdens many health professionals, and the time that would be needed for notification activities is given instead to their core professional activities. Similarly, the difficulty in perceiving ADRs lies in the confusion of symptoms with the symptomatology of patients' clinical conditions (Modesto, Ferreira, Provin, Amaral, \& Lima, 2016).

Another problem that needs to be addressed is under-reporting of ADRs, due to the lack of technical and procedural guidance, which triggers uncertainty among health professionals about how - and to whom - one should send their notification (Silva et al., 2014). A lacking understanding of the importance of reporting ADRs as part of their work routine, and fear of criticism are other causes contributing to underreporting (Modesto et al., 2016). It has furthermore been reported that many professionals do not adhere to pharmacovigilance programs because they are convinced that the drugs used in practice have been adequately tested in clinical and preclinical studies, and are therefore totally safe (Khalili, Mohebbi, Hendoiee, \& Keshtkar, 2012). This is unfortunate because low notification rates make it difficult to detect and monitor safety signs, to perform risk assessment and to take regulatory measures to protect patients.

Within this context, knowledge about the importance of pharmacovigilance procedures should be intensified, e.g., through institutional training and educational strategies (Varallo, Planeta, \& Mastroiannil, 2017). Studies show that continuing education to promote knowledge and to generate attitude changes in health care professionals may be effective, particularly when it raises awareness that activities related to pharmacovigilance belong to their duties, and will improve the safety of patients under their care (De Angelis, Colaceci, Giusti, Vellone, \& Alvaro, 2016; Mendes Marques, Polónia, Figueiras, Costa Santos, \& Herdeiro, 2016).

A study by Bretas, Silva and Nascimento (2017) demonstrated the importance of providing, within hospital environments, computerized tools to search for possible ADR. This was shown to significantly increase the identification of ADRs, and to modify the scenario where the spontaneous notification has been the main tool used (Modesto et al., 2016). Spontaneous notification is often associated with under-reporting of cases, and does not always convey necessary, early-warning signals to regulatory agencies (Silva et al., 2014). Therefore, it was suggested that active searches through trackers, via e.g., Trigger Tool methodology, implementation of computerized services that allow the tracking of information and alerts, would aid in the prevention of ADRs, reduce patient risk, decrease inappropriate prescriptions, shorten hospitalization time, and lower the associated health care costs (Mastroianni, Abjaude, \& Varallo, 2014).

Severe ADRs contribute to longer hospital stays, and increase the need for further clinical investigations. In addition, they may lead to the prescription of additional medications to treat the iatrogenic condition. A study to assess the economic burden of ADRs found that the total cost of 81 admissions triggered by ADRs was $\$ 570,404$ 
(Chan et al., 2019). In addition, there are indirect costs for patients and their caregivers, such as lost work days and morbidity related to stress or anxiety due to the episode of ADR.

In 2010, 59.8\% of the notifications made in the NOTIVISA system were made by Sentinela Network hospitals, $14.3 \%$ by health professionals, $17.6 \%$ by collaborating hospitals and $8.3 \%$ by others. The Sentinela Network hospitals were the main notifying source because their employees are motivated and qualified to report adverse events and file technical complaints about health products. In hospital settings, despite being monitored by a multidisciplinary team capable of recognizing and reporting adverse events, hospitalized patients are usually exposed to a variety of drugs and therefore susceptible to show adverse reactions, including those which may lead to death. Within this context, involvement of clinical pharmacy services has been proposed as an additional element to increase the efficiency of health systems. Evidently, clinical pharmacy services are closely involved in the control of medication-related pharmaceutical interventions by prescription review, identification of potential adverse events and drug interactions, optimization of therapy and medication reconciliation, and prescription management, multidisciplinary collaborations, and implementation of protocols and guidelines, thereby providing significant contributions to patient safety and better clinical and economic results (Kopciuch et al., 2019).

Although retrospective analysis of medical records is considered the gold standard for detecting adverse events, there are well-known limits to the utility of medical records that reflect difficulties in providing care and quality of information. For example, omitting information about a penicillin allergy from a patient's records might cause an adverse event after inadvertent administration of this medication. Thus, it is necessary that other elements, such as the electronic medical record may be added to the adverse events investigation, in order to obtain reliable data. Computerized monitoring with trackers to identify adverse drug events e.g., specific symptoms, may be an important alternative for investigating more complex trackers. However, this method may entail high costs and require the digitization of medical records.

\subsection{Notifying Professionals}

Originally, physicians were the only professionals invited to report in pharmacovigilance systems. However, several studies showed that other health care professionals were able to observe different drug-related problems, and it was decided to delegate reporting responsibility to all healthcare professionals that were involved directly with the prescription, dispensation and administration of drugs (Hornbuckle, Wu, \& Fung, 1999). The most important category of professionals providing notifications was pharmacists, followed by nurses, nursing technicians, and doctors. In spite of the broad dissemination of knowledge about pharmacovigilance programs among all health professionals, the pharmacist still remains the most actively reporting professional. Underlying factors contributing to this statistic are the better knowledge and stronger awareness among pharmacists about drug-related programs and the relevance given to notifications. Still, many professionals think that it is the pharmacy's sole responsibility to report ADRs and technical complaints (Silva et al., 2014).

Abjaude, Zanetti, Marques and Rascaldo (2013) interviewed health professionals featuring ANVISA resolutions on pharmacovigilance, adverse reactions, NOTIVISA and technical complaints, patient safety, and drug-related problems. Of the professionals that were interviewed, physicians were the professionals with the lowest level of knowledge about pharmacovigilance, but obtained $100 \%$ accuracy on the concept of adverse reactions; in contrast, pharmacists showed the least knowledge about technical complaints. There is a need to encourage interdisciplinary and multi-professional collaboration, so that the different health professionals may complement another in a collaborative network that provides active drug safety surveillance (Modesto et al., 2016).

It would also be important to highlight the role of nursing professionals, since these professionals are responsible for the daily administration of medication as well as patient care. Adverse events should become directly linked to possible systemic failures and not merely to professional errors, so that procedural weaknesses may be identified and preventive measures adopted. The most commonly occurring errors are adverse events related to drug administration, events related to maintenance of skin integrity and events related to falls (Corbellini, Lore Schilling, Frantz, Gonçalves Godinho, \& Urbanetto, 2011).

Pharmacovigilance in dentistry may play an important role in maintaining high-quality care. Not unlike other medical professionals, dentists prescribe a wide variety of medications in their clinical practice, including, most commonly, antibiotics, pain killers, anti-inflammatory drugs, and antipyretics However, there is little information in the literature about the frequency of ADRs and other reports in dental practice.

A study that assessed the dentists' attitude toward pharmacovigilance and ADR reporting indicated that while most dentists agree on the importance of reporting ADR-related cases, only a few do so actively. In addition, it was found that $51 \%$ of the dentists were unaware of how to report ADRs and $7 \%$ indicated the pharmacist as the main 
professional who should be notified (Sudhakar, Madhavan, \& Balasubraman, 2015). Although pharmaceutical professionals can indeed play a key role in handling drug safety the exchange of information related to ADRs between the dentist and other health professionals remains crucial. In sum, drug safety assessment should be considered as an indispensable aspect of the clinical practice of doctors, pharmacists, nurses, dentists, and other healthcare providers (Almandil, 2016; Varallo et al., 2017).

\section{Conclusion}

Drug therapy is the most prominent approach used by health care facilities, making the development and maintenance of pharmacovigilance systems an essential factor to ensure the safety and integrity of health system users, to reduce excessive lengths of stay and to optimize healthcare investments. However, this important tool is still undervalued, neglected or even unknown in our country. There have been several attempts to improve pharmacovigilance reporting, but they do not appear to be reflecting concrete results.

Certainly, greater awareness of professionals involved in patient care should be promoted, to install the practice of reporting drug-related negative events, so that a realistic and complete view emerges regarding treatment-related complications of any prescribed drug.

\section{Acknowledgments}

The authors thank the Coordenação de Aperfeiçoamento de Pessoal de Nível Superior - Brasil (CAPES) and Universidade Federal de Mato Grosso do Sul (UFMS). This work was supported in part by them.

\section{Competing Interests Statement}

The authors declare that there are no competing or potential conflicts of interest.

\section{References}

Abjaude, R. A. S., Zanetti, B. C. A., Marques, M. A. L., \& Rascado, R. R. (2013) [Omission in Notifications: result of ignorance in Pharmacovigilance]. Revista da Universidade Vale do Rio Verde, 11(1), 267-276. https://doi.org/10.5892/ruvrv.2013.111.267276

Almandil, N. B. (2016). Healthcare professionals' awareness and knowledge of adverse drug reactions and pharmacovigilance. Saudi Medical Journal, 37(12), 1359-1364. https://doi.org/ 10.15537/smj.2016.12.17059

Bretas, J. M., Silva, M. D. G., \& Nascimento, M. M. G. (2017). [Evaluation of the implementation of computerized tools for adverse drug reactions active surveillance]. Infarma - Ciências farmacêuticas, 29(3), 235-240. https://doi.org/ 10.14450/2318-9312.v29.e3.a2017.pp235-240. (In Portuguese)

Chan, S. L., Ng, H. Y., Sung, C., Chan, A., Winther, M. D., Brunham, L. R., \& Wee, H. L. (2019). Economic burden of adverse drug reactions and potential for pharmacogenomic testing in Singaporean adults. Pharmacogenomics Journal, 19(4), 401-410. https://doi.org/ 10.1038/s41397-018-0053-1

Corbellini, V. L., Lore Schilling, M. C., Frantz, S. F., Gonçalves Godinho, T., \& Urbanetto, J. S. (2011). [Medication-related adverse events: percepception of nursing aides]. Revista Brasileira de Enfermagem [online], 64(2), 241-247. https://doi.org/ 10.1590/S0034-71672011000200004

Dainesi, S. M. (2005). Pharmacovigilance: more than ever, an overall responsibility. [farmacovigilância: cada vez mais, um dever de todos]. Clinics, 60(4), 267-70. https://doi.org/10.1590/S1807-59322005000400002

De Angelis, A., Colaceci, S., Giusti, A., Vellone, E., \& Alvaro, R. (2016). Factors that condition the spontaneous reporting of adverse drug reactions among nurses: an integrative review. Journal of Nursing Management, 24(2), 151-163. https://doi.org/ 10.1111/jonm.12310

Gomes, V. P., Silva, M. T., \& Galvão, T. F. (2017). Prevalence of medicine use among Brazilian adults: a

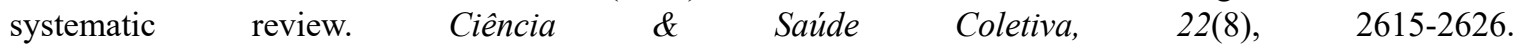
https://doi.org/10.1590/1413-81232017228.29412016

Hazell, L., \& Shakir, S. A. (2006). Under-reporting of adverse drug reactions: a systematic review. Drug Safety, 29(5), 385-396. https://doi.org/10.2165/00002018-200629050-00003

Hornbuckle, K., Wu, H. H., \& Fung, M. C. (1999). Evaluation of spontaneous adverse event reportsby primary reporter - a 15-year review (1983 to 1997). Drug Information Journal, 33, 1117-1124. https://doi.org/10.1177/009286159903300416

Khalili, H., Mohebbi, N., Hendoiee, N., \& Keshtkar, A. (2012). Impro-vement of knowledge, attitude and perception of health-care workers about Adverse Drug Reactions, a pre-and post-clinical pharmacists' interventional study. BMJ Open, 2(1), e000367. https://doi.org/ 10.1136/bmjopen-2011-000367 
Kopciuch, D., Zaprutko, T., Paczkowska, A., Ratajczak, P., Zielińska-Tomczak, L., Kus, K., \& Nowakowska, E. (2019). Safety of medicines-Pharmacists' knowledge, practice, and attitudes toward pharmacovigilance and adverse drug reactions reporting process. Pharmacoepidemiology Drug Safety, 28(12), 1543-1551. https://doi.org/10.1002/pds.4792

Mastroianni, P. C., Abjaude, S. A. R., \& Varallo, F. R. (2014). [Reviews on Pharmacoeconomic Drug Surveillance]. Revista Saúde \& Ciências Online, 3(2), 43-57. Retrieved July 20, 2018, from http://www.ufcg.edu.br/revistasaudeeciencia/index.php/RSC-UFCG/article/download/103/89 (In Portuguese)

Menard, M. L., Thümmler, S., Giannitelli, M., Olliac, B., Bonnot, O., Cohen, D., \& Askenazy, F. (2016). Incidence of adverse events in antipsychotic-naïve children and adolescents treated with antipsychotic drugs: a French multicentre naturalistic study protocol (ETAPE). BMJ Open, 6(4), e011020. https://doi.org/10.1136/bmjopen-2015-011020

Mendes Marques, J. I., Polónia, J. M., Figueiras, A. G., Costa Santos, C. M., \& Herdeiro, M. T. (2016). Nurses' attitudes and spontaneous adverse drug reaction reporting: a case-control study in Portugal. Journal of Nurssing Management, 24(3), 409-416. https://doi.org/10.1111/jonm.12337

Modesto, A. C. F., Ferreira, T. X. A. M., Provin, M. P., Amaral, R. G., \& Lima, D. M. (2016). [Pharmacovigilance: Professional Knowledge and Conduct at a Teaching Hospital.] Revista Brasileira de Educação Médica, 40(3), 401-410. https://doi.org/ 10.1590/1981-52712015v40n3e01502015

Pepe, V. L. E., \& Novaes, H. M. D. (2020) National Pharmacovigilance Systems in Brazil and Portugal:similarities, differences, and challenges. Cadernos de Saúde Pública; 36(7), e00043019. https://doi.org/10.1590/0102-311x00043019

Silva, P. L., Cornélio, R. A. C., Araujo, A., \& Da, L. A. (2014). [Pharmacovigilance: Knowledge And Action Of The Professionals Facing The Deviations Of Quality Of Medicines]. Revista Brasileira de Farmácia Hospitalar e Serviços de Saúde, 5(1), 33-37. Retrieved July 20, 2019, from https://www.rbfhss.org.br/sbrafh/article/view/185

Sudhakar, S., Madhavan, A., \& Balasubraman, S. (2015). Attitude of dentists toward pharmacovigilance and reporting adverse drug reactions: A cross-sectional study. Journal of Advanced Clinical and Research Insights, 2, 242-247. https://doi.org/ 10.15713/ins.jcri.87

Varallo, F. R., Planeta, C. S., \& MastroianniI, P. C. (2017). Effectiveness of ph rmacovigilance: multifaceted educational intervention related to the knowledge, skills and attitudes of multidisciplinary hospital staff. Clinics, 72(1), 51-57. https://doi.org/10.6061/clinics/2017(01)09

Wiktorowicz, M., Lexchin, J., \& Moscou, K. (2012). Pharmacovigilance in Europe and North America: Divergent approaches. Social Science \& Medicine, 75(1), 165-170. https://doi.org/10.1016/j.socscimed.2011.11.046

World Health Organization [WHO]. (2015). Fast facts on pharmacovigilance. Retrieved July 23, 2019, from https://www.who.int/medicines/areas/quality_safety/safety_efficacy/PV_fast_facts/en/

World Health Organization [WHO]. (2002). The importance of pharmacovigilance: safety monitoring of medicinal products. Retrieved July 23, 2019, from https://apps.who.int/medicinedocs/pdf/s4893e/s4893e.pdf

\section{Copyrights}

Copyright for this article is retained by the author(s), with first publication rights granted to the journal.

This is an open-access article distributed under the terms and conditions of the Creative Commons Attribution license (http://creativecommons.org/licenses/by/4.0/). 